\title{
Probabilistic Determination of Consumers Response and Consumption Management Strategies in Demand Response Programs
}

\author{
Andrea Bortolato, Pedro Faria and Zita Vale \\ Polytechnic of Porto \\ Porto, Portugal \\ andrea.bortolato.6@studenti.unipd.it; pnf@isep.ipp.pt; zav@isep.ipp.pt
}

\begin{abstract}
In Demand Response programs, the response of the users to the event request depends on several factors. In this paper, a method that examines the response of the consumers to a load reduction request, defining the context in which the demand response event is carrying on and studying how the consumers react, is proposed. Statistical methods are used. Then are proposed several strategies to optimize the consumers' participation in the load reduction basing the optimization on the previous characterization.
\end{abstract}

Keywords- Demand Response, Performance Evaluation, Smart Grids, Uncertainty

\begin{tabular}{ll} 
& \multicolumn{1}{c}{ NoMENCLATURE } \\
$p$ & Performance \\
$p_{\text {avg }}$ & Average performance \\
$b$ & Baseline value \\
$a$ & Adjustment values \\
$c$ & Shedline value \\
$e$ & Duration of the event \\
$\mu$ & Parameter's mean \\
$\sigma$ & Standard deviation \\
Pr\%norm & Probability in Normal distribution \\
Pr\%kern & Probability in Kernel distribution
\end{tabular}

\section{INTRODUCTION}

In the last decade, the construction of new renewable power plants is grown exponentially; in an IEA [1] report, installed renewable-based generation capacity of $1985 \mathrm{GW}$ in 2015 was mentioned, exceeding for the first time the coal plants capacity (1950 GW). Wind capacity was $35 \%$ higher than the previous year and solar photovoltaic increased by almost $25 \%$. IEA estimates the installation of $4000 \mathrm{GW}$ of new renewable capacity until 2040. Moreover, electrical consumption will grow up to $34000 \mathrm{TWh}$, about $70 \%$ more than now, due to the higher presence of heat pumps, cooking induction systems and electric vehicle [1].

Electrical grids get updated with sensors and data collector appliance to become intelligent systems, defined as Smart

The present work was done and funded in the scope of the following projects: UID/EEA/00760/2013 funded by FEDER Funds through COMPETE and National Funds through FCT; SPEAR project co-funded by Portugal 2020 "Fundo Europeu de Desenvolvimento Regional” (FEDER) through PO CI.
Grids (SGs), able to reply to the significant challenges to the secure operation and planning of power systems [2]. A smart grid is an electric grid that can deliver electricity in a controlled and smart way from point of generations to consumers, who are considered as an integral part of the SG [3]. End-use customers become also an active part of the grid because they can modify their consumption patterns and behaviours according to the information, incentives or disincentives communicated by the grid operator.

Demand Side Management (DSM) includes everything that is done in the demand side of an energy system, from an improvement in energy efficiency, to the investment in a load management system which helps consumers to reduce their bills by shifting electricity use to less expensive hours or turn off unnecessary appliances during the most expensive electricity price hours [2]. A specific concept in DSM is Demand Response (DR). As defined in [4], DR refers to "changes in electric usage by end-use customers from their normal consumption patterns in response to changes in the price of electricity over time, or to incentive payments designed to induce lower electricity use at times of high wholesale market prices or when system reliability is jeopardized".

Assuming that the answer to a demand response call is not mandatory and it is a customers' decision to participate or not, and in which quantity, to a DR event, the prediction of the consumers' participation is not so easy. So, the participation cannot follow the operator's expectations. In [5] are reported many consumers barriers which can compromise the result of a DR event:

- Consumer knowledge: many people have very little knowledge about how the electricity market works and about the relation between appliances usage and electricity consumption.

- Availability of technology: as electricity users need to know the price of the electricity, utility providers need to be able to precisely know the real-time consumption of their customers to guarantee the right incentives.

- Information feeds: to obtain information about prices and consumption could be very hard for the customers, then they aren't encouraged to save energy even in the presence of money savings because the cost to have this information and understand them is higher than the economic benefits.

In general, if costumers have access to additional information, as in-home display indicating the current price or the amount that can be saved, responses are greater [6]. 
To overcome these issues, an Automate Demand Response (ADR) approach can be implemented in buildings. The ADR doesn't involve human intervention and it is initiated at a home, building or facility through receipt of an external communications signal, the receipt of the signal initiates preprogrammed demand response strategies [7]. Most of the fully automated strategies can be split into these categories [8]: Heating, ventilation and air conditioning (HVAC); Lighting; Other actions are antisweat heater shed, fountain pump turnoff and noncritical process shed.

When an Auto-DR strategy incurs, the homeowner or the facility manager should be able to override the DR event if the event comes at a time when the reduction of the end-use services is not desirable; moreover it's also important to point out that if the appliances normally involved in the Auto-DR strategy are already off before the beginning of the event the power reduction won't follow the expectations and the load shed could fail for that user.

The present paper proposes an innovative method that allows the grid operator to have a probabilistic determination of the consumers' response in a DR event. Given a set of previous events with the respective actual responses of each consumer, the performance of the consumer participation in the DR event is evaluated and quantified. This allows the network operator or an aggregator to more accurately schedule the DR resources or consumers, taking into account the probability of response of each consumer.

Section I shows the introduction to the topic. In section II, all phases of the proposed model and studied through the case of study which is presented in section III are discussed in detail. The results of the selected scenario will be analysed in section IV. Finally, section V presents the main conclusions.

\section{APPROACH}

This section presents the proposed method; the first part of the method aims to define the behaviour of the users in a DR program, in different contexts, in order to identify when each customer is more useful to the electric system and how much it can influence the objective of a DR event. Fig.1. gives a basic view of the structure of the proposed method.

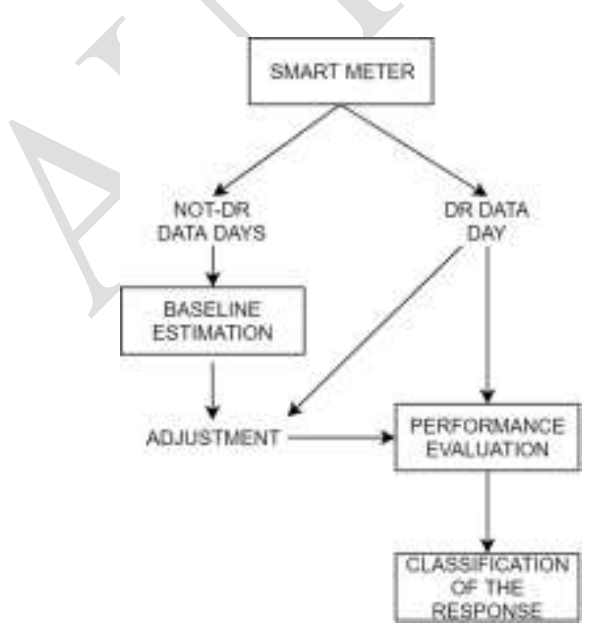

Fig. 1. Structure of the method
The first step is to obtain data about electricity consumption through a smart meter. After the data collection, it's necessary to define the load profile of the user; to do that the techniques described in [9] and [10] can be used for the baseline calculation. The forecasting of a baseline that is very similar to the real load profile is fundamental to have a good evaluation of the performance that the customer can achieve and then it is also very important for the characterization of the consumer's response. To define the results of a DR event have been chosen three performance indexes defined in [9],[11]. The performance " $p$ " (1) is the difference between the adjusted baseline and consumption during the event.

$$
p=\sum_{i=0}^{e}\left(b_{i}+a\right)-c_{i}
$$

The capacity-setting performance " $p_{\text {avg }}$ " (2) is given by the average performance during all intervals of the DR event.

$$
p_{\text {avg }}=\frac{\sum_{i=0}^{e}\left(b_{i}+a\right)-c_{i}}{e}
$$

Then, the last parameter that could be useful is the change in total electricity consumption during peak hours (3).

$$
\frac{\text { orig.peak.consum. -new.peak.consum. }}{\text { orig.peak.consum. }}
$$

As the method is strutured, the most useful index is the performance. Every context has its duration then the comparison is always done with events that have the same time length. In Fig. 2. the first part of the method is represented: from the input data to the density distribution of the parameters considered. 


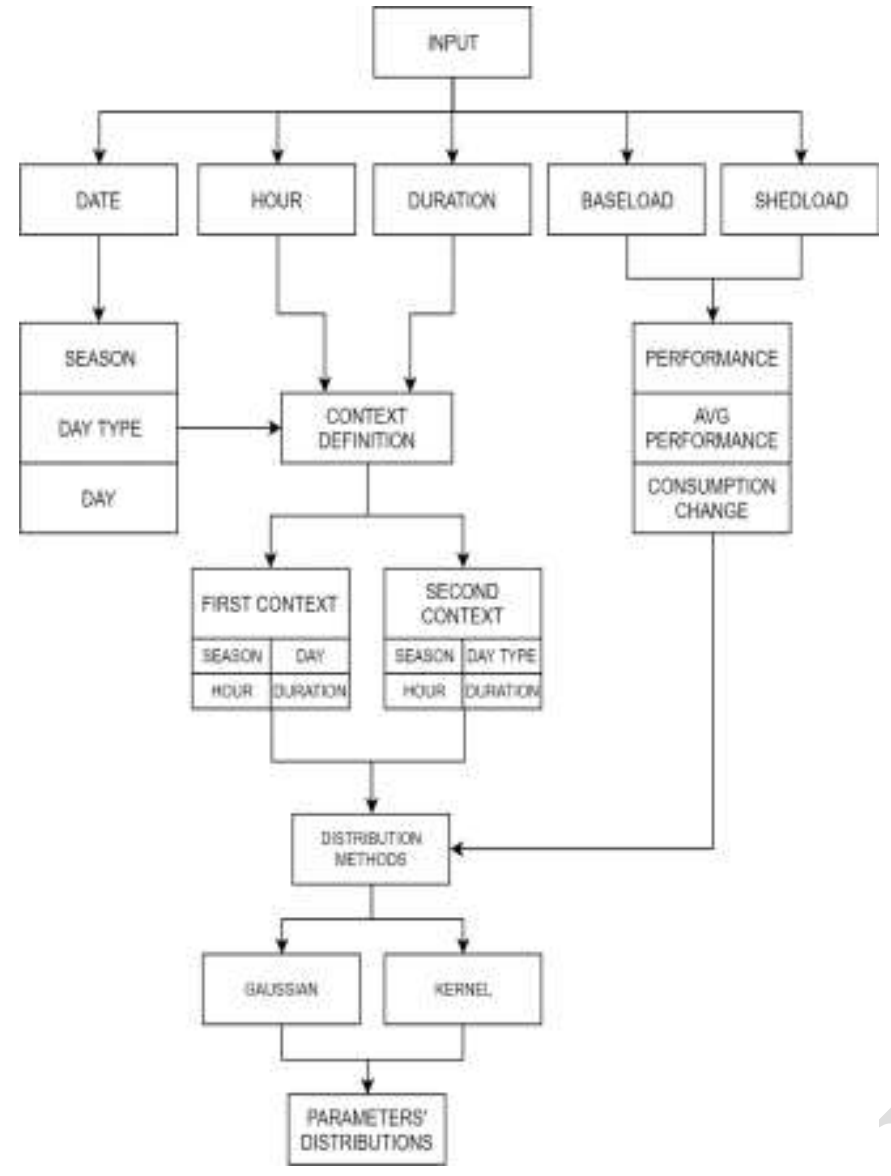

Fig. 2. Definition's scheme of the parameters' distribution

The input file must contain the date of the event, the time in which the DR event occurred and the duration of the event to define the context in which the event performed then the baseline and the shedline are necessary to extract the performance indexes previously described. Once that parameters and contexts have been linked, two distribution methods are applied to these data to understand how all the events with the same context are distributed and then, a probabilistic value of the answer of the consumer can be obtained. The two distributions approaches that have been chosen are the Gaussian distribution and the Kernel distribution. The Gaussian distribution describes well most of the events linked to the probability (4).

$$
f(x)=\frac{1}{\sigma \sqrt{2 \pi}} e^{-\frac{(x-\mu)^{2}}{2 \sigma^{2}}}
$$

Using (4), it is possible to obtain the normal density distribution of the parameter considered. However, it may be not realistic in the field of demand response assuming normality in the distribution flexibility so, as the first approach, waiting for enough data for verification of the distribution shape, it is proposed to use also the Kernel method [12]. This method is interesting because no distribution scheme is supposed, the curve is shaped depending on the data and the frequency that the values appear in different ranges. The Kernel density estimator's formula, for any real values of $\mathrm{x}$, is given by (5).

$$
\widehat{f}_{h}(x)=\frac{1}{n h} \sum_{i=1}^{n} \boldsymbol{K}\left(\frac{x-x_{i}}{h}\right)
$$

Where $\mathrm{x}_{1}, \mathrm{x}_{2}, . ., \mathrm{x}_{\mathrm{n}}$ are random samples from an unknown distribution, $\mathrm{n}$ is the sample size, $\mathrm{K}(\cdot)$ is the Kernel smoothing function and $\mathrm{h}$ the bandwidth [13].

Once the parameters' distributions are calculated, it's possible to define which is the optimal amount of electricity that is possible to obtain from each consumer. The objective is to know the amount of electricity that each user can reduce with a high probability. As the first step, it is necessary to define the context in which we are interested to investigate and then define the amount of electricity that we would like to obtain from that specific user.

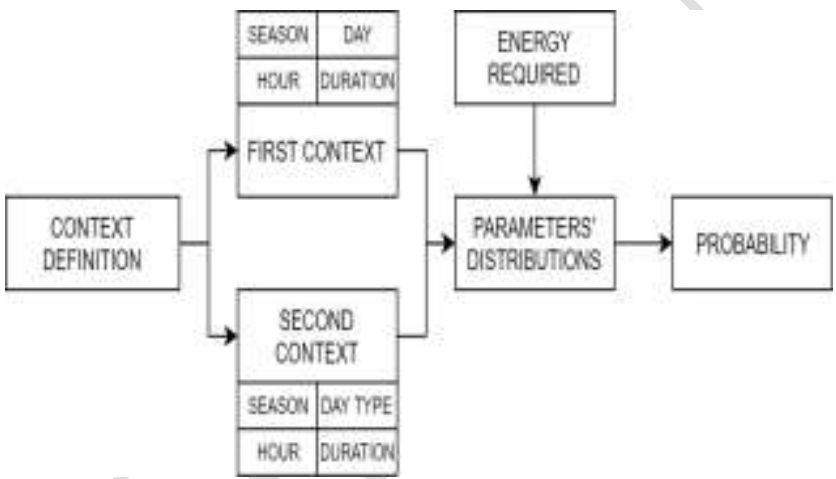

Fig. 3. Probability's shed definition

In a normal distribution, the probability is defined as (6).

$$
P r_{0 \text { norm }}=\int_{a}^{b} f(x) \partial x \quad \times 100
$$

Instead in presence of a Kernel distribution, the probability is defined as (7).

$$
P r_{\% \text { kern }}=\int_{a}^{b} \frac{1}{n h} \sum_{i=1}^{n} \boldsymbol{K}\left(\frac{x-x_{i}}{h}\right) \partial x \quad \times 100
$$

Using the procedures described until now it is possible to obtain the characterization of the users involved in DR programs and to define, for each one of these users, the amount of electricity that is available for a DR event in a defined context. As in an ADR program the aggregators are the ones who sent a signal to activate the DR strategies, these pieces of information should be used by them to determine who are the consumers that better can perform the load shed request. To find the best combination of users that better fit the requests of the aggregators; to do that the sum of the probability density parameters that have been calculated in the previous step is required. In the probabilistic field it is well known that the probability distribution of the sum of two or more independent variables is the convolution of their distribution [14]. This method can be used with both probability density function previously illustrated.

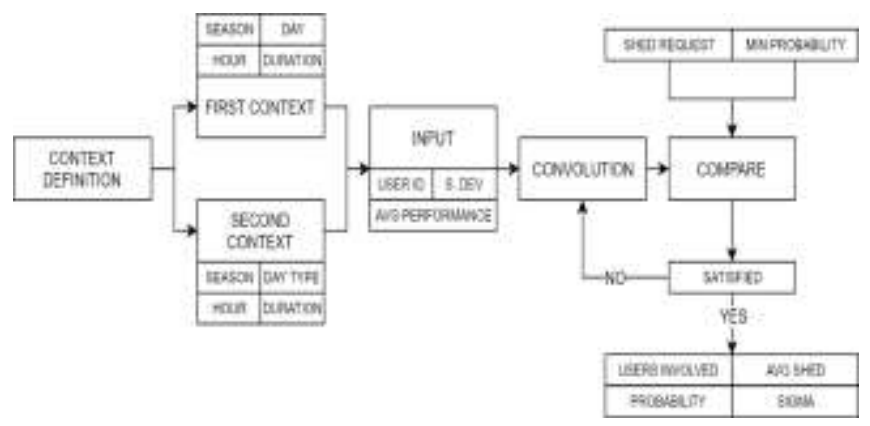


Fig. 4. Convolution strategy for consumers' managing in DR events

The users' order, with which the convolution occurs, influences the number and which user is involved in the event because when the aggregators' requests are satisfied the convolution stops. There are several ways in which users can be ordered. Users' classification ordered by the standard deviation in increasing order, the ratio between average performance and standard deviation value and a convolution including all the consumers have been tested. After every convolution, the power that has to be cut and the probability to have this amount of power is compared with the request of the aggregators. If the requests are satisfied, the convolution process stops and are obtained pieces of information about the users that have to be involved, the forecast average shade, the probability of the required shed and the standard deviation of the convolution, that is an index of the uncertainty of the shed level.

\section{USED DATA}

In this section, the case study used to verify the functionality of the method is introduced. The data used to test this method is the property of the New Thames Valley Vision (NTVV) - www.thamesvalleyvision.co.uk . The NTVV is a Low Carbon Network Fund Tier 2 project selected by Ofgem during the 2011 competitive selection process. Focussed on the low voltage network, the NTVV aims to demonstrate how electricity distribution networks can better serve their customers by understanding, anticipating and supporting their energy use as they move towards low carbon technologies [15]. One of the projects conducted by the NTTV involved the Automated Demand Response. To put in practice this project, 30 different types of buildings were enrolled, such as commercial, hospitality, leisure, healthcare, data centres, educational or public sector buildings with an aggregated load reduction of more than 1,1 MW. For each ADR event a file with information about the power consumption on the day of the DR event and the baseline is available. The data refer to three events, for each building, carried out during the autumn at 16:00 System Peak with a duration of two hours; the buildings involved are two educational centres, a local office and a leisure centre. The power data are composed by a sample every 15 minutes [12].

\section{RESULTS}

Throughout this section, the results of the method test, conducted by implementation in RStudio, are presented; the purpose of the results reported is to show that the method works, how it works and the results that are possible to obtain; the data available aren't enough to determine a real characterization of the buildings involved in the trial.

The first part of the method concerns the analysis of each building. The results of the analysis of an educational building are reported.

TABLE I.

CONTEXT OF ANALYSED DATA

\begin{tabular}{|c|c|c|c|c|}
\hline Season & Day & Day Type & Event Time & Duration \\
\hline Autumn & Tues day & Weekday & $16: 00$ & $2 \mathrm{~h}$ \\
\hline
\end{tabular}

Table I. reports the context in which the analysis has been conducted. The summary of the performance indexes obtained from the educational building is reported in Table II. In the normal distribution, we obtained a performance curve with an average performance of $7,78 \mathrm{kWh}$ and a standard deviation of $5,50 \mathrm{kWh}$. The standard deviation seems to be very high, mainly compared with the average performance and this is due to the great variability of the performance measured. To reduce the uncertainty in the distribution a quite high number of events on the same context is required to have a bigger set of performance values, moreover, good quality of the baseline prediction is necessary. The baseline is essential for the determination of the performance, then, very high variability in the performance values could be also due to a not good baseline prediction.

However, though the values analysed show a big uncertainty, the shape of the curve with a Kernel distribution (Fig. 6.) is comparable with the curve using the Gaussian distribution (Fig. 5.). The smoothness of the curve depends on the bandwidth $h$ in the equation (5), a bigger value of $h$ leads to a smoother curve instead a lower value of $h$ leads to a curve in which the single contributes are more visible; in this method an optimal value of $h$ is chosen by the optimization algorithm implemented in the R's kernel distribution method.

TABLE II. SUMMARY OF THE EVENTS IN THE EDUCATIONAL BUILDING

\begin{tabular}{|c|c|c|c|}
\hline Date & $\begin{array}{c}\text { Performance } \\
{[\mathrm{kWh}]}\end{array}$ & $\begin{array}{c}\text { Avg Performance } \\
{[\mathrm{kWh}]}\end{array}$ & $\begin{array}{c}\text { Consumption } \\
\text { change \% }\end{array}$ \\
\hline $04 / 10 / 2016$ & 8 & 4 & 12,7 \\
\hline $25 / 10 / 2016$ & 13,16 & 13,16 & 21,52 \\
\hline $08 / 11 / 2016$ & 2,17 & 1,08 & 3,38 \\
\hline
\end{tabular}

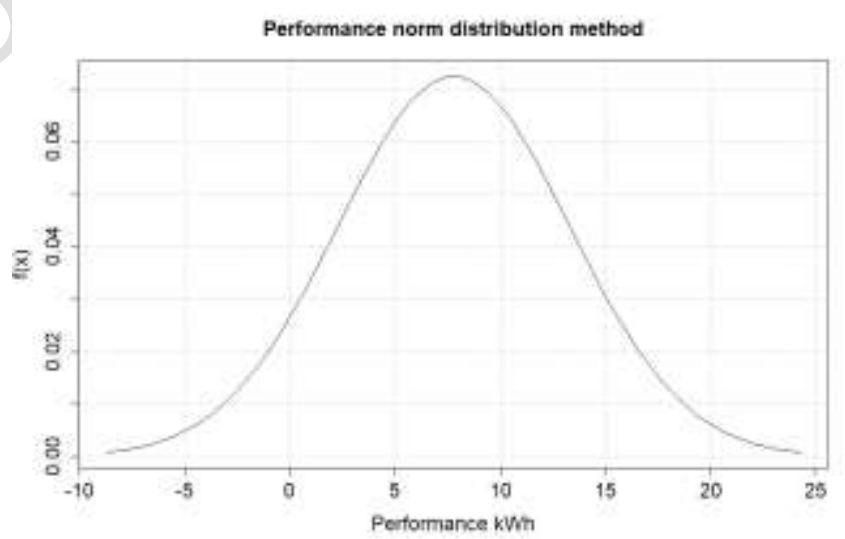

Fig. 5. Performance's normal distribution educational building 


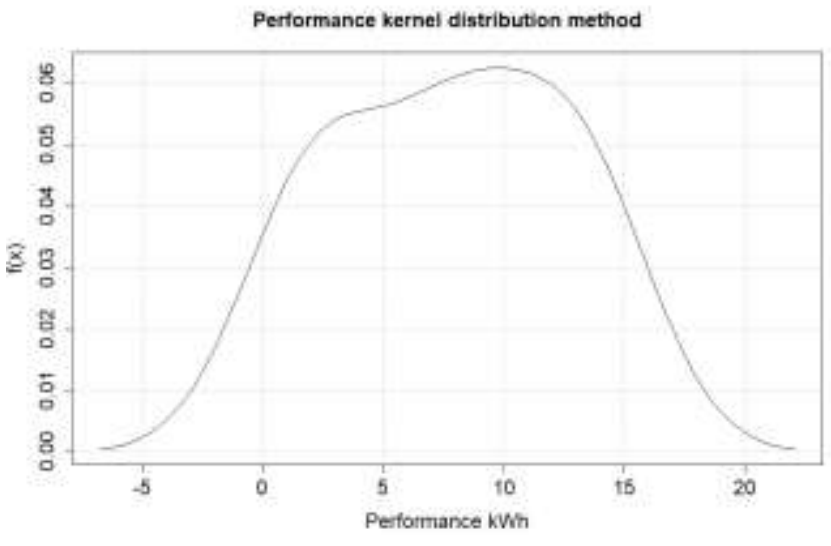

Fig. 6. Performance's kernel distribution educational building

Table III. shows the comparison between the probabilities calculated with the two different distribution functions, considering several values of saved power.

TABLE III. SUMMARY OF DIFFERENT PERFORMANCE PROBABILITIES

\begin{tabular}{|c|c|c|c|c|c|}
\hline \multirow{2}{*}{ Probability \% } & \multicolumn{5}{|c|}{ Min Performance [kWh] } \\
\cline { 2 - 6 } & 0 & 5 & 10 & 15 & 20 \\
\hline Normal & 92,54 & 70,78 & 36,2 & 10,44 & 1,46 \\
\hline Kernel & 93 & 69,59 & 38,12 & 10,78 & 0,35 \\
\hline
\end{tabular}

The probabilities calculated using the two methods are almost the same and, moreover, the probabilities calculated with the Kernel function, that should better represent the real distribution of the performance values, seem to be less precautionary then the normal distribution; so, at least for this user, it is possible to affirm that the Gaussian distribution function can be used as a distribution method facilitating all the following data processing. The second part of the method concerns the different strategies to manage consumers during a DR event. To test the methods four different users have been considered as participants to the DR program, these consumers had these characteristics.

The performances reported in the Table IV are the mean of the performances considered for each building and the relative standard deviations. The tests refer to a required performance of $10 \mathrm{kWh}$ with a probability at least equal to $70 \%$. Classifying users on the standard deviation in increasing order the convolution of a new consumer follows this users' sequence: $4,3,1,2$. To achieve the result of the required load shedding it is necessary to involve the first three customers of the sequence. Involving these three users in the DR event it is possible to obtain a load shed of $10 \mathrm{kWh}$ with a $93,9 \%$ probability of success. The average performance, i.e. the performance with the $50 \%$ of probability that can be reached or exceeded, is equal to $19 \mathrm{kWh}$ with a standard deviation of $6 \mathrm{kWh}$.

TABLE IV. LIST OF THE USERS INVOLVED IN THE METHOD TEST

\begin{tabular}{|c|c|c|c|}
\hline User ID & Building & $\begin{array}{c}\text { Performance } \\
{[\mathrm{kWh}]}\end{array}$ & $\begin{array}{c}\text { Standard deviation } \\
{[\mathrm{kWh}]}\end{array}$ \\
\hline 1 & Educational 1 & 7,78 & 5,5 \\
\hline 2 & Educational 2 & 17,55 & 11,81 \\
\hline 3 & Office & 4,08 & 3,42 \\
\hline 4 & Leisure Centre & 7,19 & 1,58 \\
\hline
\end{tabular}

Achieving the results of a load reduction of, at least, 10 $\mathrm{kWh}$ with a minimum probability equal to $70 \%$ requires the involvement of the users 4, 2 and 1. In this case, Educational Centre 1 joins the event because the relation between the energy that it can reduce, and the uncertainty is better than of other consumers. With these three users involved in the DR event it is possible to obtain a load shed of $10 \mathrm{kWh}$ with a $98,4 \%$ probability of success. The average performance is equal to $32,53 \mathrm{kWh}$ with a standard deviation of $10,84 \mathrm{kWh}$.

Then a test in which all the four user performances' distributions have been convoluted has been conducted, as in Table 5. The result is an average performance of $36,60 \mathrm{kWh}$ with a standard deviation of $11 \mathrm{kWh}$. Despite the involving of consumers which have been considered worse in the previous strategies, this strategy has the highest ratio performance / standard deviation. Looking at the required performance of $10 \mathrm{kWh}$, the probability that it happens is equal to $99,31 \%$. In the case of a contribution in power reduction that is coming from a larger consumers group than the necessary, it could be enough asking for a lower load shed than the one plan in the strategy implemented in the ADR, with a higher chance of success.

TABLE V. SUMMARY OF TESTS RESULTS

\begin{tabular}{|c|c|c|c|c|c|}
\hline Test case & $\begin{array}{c}\text { Users } \\
\text { involved }\end{array}$ & $\begin{array}{c}\text { Request } \\
{[\mathrm{kWh}]}\end{array}$ & $\begin{array}{c}\text { Probablity } \\
\%\end{array}$ & $\begin{array}{c}\text { Avg } \\
\text { Shedding } \\
{[\mathrm{kWh}]}\end{array}$ & $\begin{array}{c}\text { Std. } \\
\text { Deviation } \\
{[\mathrm{kWh}]}\end{array}$ \\
\hline 1 & $3(4,3,1)$ & 10 & 93,89 & 19 & 6 \\
\hline 2 & $3(4,2,1)$ & 10 & 98,97 & 32,53 & 10,84 \\
\hline 3 & 4 & 10 & 99,32 & 36,61 & 11,07 \\
\hline
\end{tabular}

The grid operator can choose which approach is better to use: the lowest uncertainty, i.e. the lowest standard deviation, belongs to the method in which the users have been ordered following an increase in standard deviation. The method in which the users have been ordered following a decrease ratio between performance and standard deviation has a higher uncertainty, but the request should be satisfied with a higher probability.

\section{CONCLUSIONS}

In the next years, our life will depend on electricity more than now. The consumers need to become an active part in the chain of the electric energy. With a high penetration of smart appliances, it could be difficult, also for a welleducated consumer, managing the use of all the appliances in the best way. ADR can constitute a very good way to obtain good results.

The proposed method can be a useful support element for the aggregator's decisions. It also constitutes a good starting point for further improvement, additions and studies. Future work can include the addition of clustering to the method and to verify if consumers with a comparable load profile have comparable performances or if the users need to be clustered according to their response.

\section{REFERENCES}

[1] International Energy Agency, World Energy Outlook 2016. 2016.

[2] A. Losi, P. Mancarella, and A. Vicino, Integration of Demand Response Into the Electricity Chain. 2015.

[3] P. Siano, "Demand response and smart grids - A survey," Renew. Sustain. Energy Rev., vol. 30, pp. 461- 
478, 2014.

[4] DOE, "Benefits of Demand Response in Electricity Markets," no. February, 2006.

[5] J. H. Kim and A. Shcherbakova, "Common failures of demand response," Energy, vol. 36, no. 2, pp. 873-880, 2011.

[6] B. Parrish, R. Gross, and P. Heptonstall, "On demand: Can demand response live up to expectations in managing electricity systems?," Energy Res. Soc. Sci., vol. 51, no. November 2018, pp. 107-118, 2019.

[7] M. A. Piette, D. S. Watson, N. Motegi, S. Kiliccote, and E. Linkugel, "Participation through Automation: Fully Automated Critical Peak Pricing in Commercial Buildings," 2006 ACEEE Summer Study Energy Effic. Build., no. 150, 2006.

[8] P. Stluka, "Automated Demand Response for Smart Buildings and Microgrids : The State of the Practice and Research Challenges," no. February 2016, 2017.

[9] EnerNOC, "The Demand Response Baseline," no. October, pp. 1-15, 2008.

[10] P. Faria, Z. Vale, and P. Antunes, "Determining the Adjustment Baseline Parameters to Define an Accurate Customer Baseline Load," 2013 IEEE Power Energy Soc. Gen. Meet., vol. 2011, pp. 1-5, 2013.

[11] G. Thanos et al., "Evaluating demand response programs by means of key performance indicators," 2013 5th Int. Conf. Commun. Syst. Networks, COMSNETS 2013, no. May 2014, 2013.

[12] M. Vallés, A. Bello, J. Reneses, and P. Frías, "Probabilistic characterization of electricity consumer responsiveness to economic incentives," Appl. Energy, vol. 216, no. January, pp. 296-310, 2018.

[13] N. Altman and C. Léger, "Bandwidth selection for kernel distribution function estimation," J. Stat. Plan. Inference, vol. 46, no. 2, pp. 195-214, 1995.

[14] R. D. Badinelli, "Approximating probability density functions and their convolutions using orthogonal polynomials," Eur. J. Oper. Res., vol. 95, no. 1, pp. 211-230, 1996.

[15] L. O. Report, "New Thames Valley Vision Learning Outcome Report Impact on DNO Network from Low Carbon Promotions." 